\title{
The p75 neurotrophin receptor appears in plasma in diabetic rats-characterisation of a potential early test for neuropathy
}

\author{
L. Chilton ${ }^{1}$ A. Middlemas ${ }^{1}$ - N. Gardiner ${ }^{1}$ D. R. Tomlinson ${ }^{1}$ \\ ${ }^{1}$ Division of Neuroscience, Faculty of Life Sciences, University of Manchester, Manchester, UK
}

\begin{abstract}
Aims/hypothesis. This study tested the premise that immunoreactivity representing the p75 neurotrophin receptor $\left(\mathrm{p} 75^{\mathrm{NTR}}\right)$ appears in plasma of diabetic rats in association with the early stages of neuronal dysfunction or damage. We also examined whether treatment beneficial to neuropathy might reduce the $\mathrm{p} 75^{\mathrm{NTR}} \mathrm{im}-$ munoreactivity.

Methods. Plasma proteins were fractionated by SDSPAGE and immunoblots exposed to p75 $5^{\mathrm{NTR}}$ antibody, using receptor protein from cultured PC12 cells as an external standard. Rats were made diabetic with streptozotocin for various periods and exsanguinated. Plasma glucose, $\mathrm{HbA}_{1} \mathrm{c}$ and plasma proteins were determined. We also studied plasma samples from diabetic mice lacking the gene coding for $\mathrm{p} 75^{\mathrm{NTR}}$, as well as the effect of sciatic nerve crush on healthy male Wistar rats.

Results. Plasma $\mathrm{p} 75^{\mathrm{NTR}}$ immunoreactivity began to exceed normal levels at 8 weeks after induction of di-
\end{abstract}

abetes, and was significantly raised at $10(p<0.05)$ and 12 weeks $(p<0.001)$. Treatment between 8 and 12 weeks with insulin, fidarestat (an aldose reductase inhibitor), nerve growth factor and neurotrophin 3 all normalised the plasma p75 NTR immunoreactivity. Plasma from p75 NTR (-/-) mice contained no such immunoreactivity, though it was present in plasma from wild-type mice. Following nerve crush, p75 NTR immunoreactivity appeared in plasma of non-diabetic mice, indicating that this can be a result of nerve trauma.

Conclusions/interpretation. These observations suggest that plasma p75 $\mathrm{NTR}$ immunoreactivity may serve as an early indicator of neuronal dysfunction or damage in diabetes. The time course of its appearance relates well to that of early neuropathy and its response to interventions that are neuroprotective suggests that it might mirror neurological status.

Keywords Nerve growth factor - Neuropathy · Neurotrophins · p75 ${ }^{\mathrm{NTR}} \cdot$ Plasma marker · Rats · Receptor shedding
Received: 26 May 2004 / Accepted: 18 July 2004

Published online: 19 November 2004

(C) Springer-Verlag 2004

D. R. Tomlinson (

Division of Neuroscience, Faculty of Life Sciences,

University of Manchester, Stopford Building,

Oxford Road, Manchester, M13 9PT, UK

E-mail: david.tomlinson@man.ac.uk

Tel.: +44-161-2755769, Fax: +44-161-2755767

Abbreviations: IR, immunoreactivity $\cdot$ NGF, nerve growth factor $\cdot \mathrm{NT}-3$, neurotrophin $3 \cdot \mathrm{p} 75^{\mathrm{NTR}}$, neurotrophin receptor of molecular weight $75 \mathrm{M}_{\mathrm{r}} \cdot \mathrm{STZ}$, streptozotocin

\section{Introduction}

The generic phenomenon of receptor shedding, with consequent appearance (either de novo or in increased titre) in plasma, has been studied in several disease states. Most of the relatively small amount of published work is recent (later than 1995) and concentrates on receptors for cytokines and adhesion molecules. Thus, TNF- $\alpha$ receptors are shed in association with neoplasia [1, 2], osteoarthritis [3], retinal diseases (not including diabetic retinopathy) [4] and asthma [5]. Other cytokine receptors are shed in inflammatory bowel disease [6, 7] and osteoarthritis [8]. Receptors for adhesion molecules are shed in relation 
to leucocyte activation $[9,10]$ and in neoplasia [11]. The extent to which these observations are suggestive of mechanisms varies; nevertheless, they may have diagnostic potential purely on pragmatic grounds.

No systematic studies are described in the literature on shedding of neurotrophin receptors. There are two receptors involved in transduction of the neuronal response to nerve growth factor (NGF). Neurotrophin selectivity is conferred by the high-affinity receptor trkA, but binding and internalisation of NGF into the neurone are facilitated by, if not actually dependent on a second, low-affinity receptor, neurotrophin receptor of apparent molecular weight $75 \mathrm{M}_{\mathrm{r}}\left(\mathrm{p} 75^{\mathrm{NTR}}\right.$; see [12] for review). This latter receptor is directly analogous in structure and cellular disposition to the p75 TNF- $\alpha$ receptor, prompting speculation that shedding behaviour exhibited by the TNF variant (referred to above) may be shared by the NGF $\mathrm{p} 75$ receptor.

The $\mathrm{p} 75^{\mathrm{NTR}}$ was purified from tissue sources some years ago, antibodies were raised and a truncated form (p50), expressed particularly by Schwann cells, was found to contain a similar epitope to the mature receptor [13]. This same antibody was also used to demonstrate p75-like immunoreactivity in the urine of diabetic patients diagnosed with neuropathy [14]. Details of this last observation are scant, in that the antibody used was not monoclonal, there was not an acceptable fractionation of the proteins before immunocharacterisation, relationships between plasma and urine levels of immunoreactivity were not determined and neurological characterisation of the patients was either rudimentary or under-reported. Nevertheless, the observation has enormous potential. The aim of the present study was to determine whether circulating p75 immunoreactivity can be detected in plasma from rats with experimental diabetes. That done, the secondary aims were characterisation of the immunoreactivity and examination of the effects, in diabetic rats, of several interventions that might be expected to ameliorate neurological stress or damage. Thus, we sought to lay a foundation for the development of plasma $\mathrm{p} 75^{\mathrm{NTR}}$ immunoreactivity as a surrogate marker for small fibre neuropathy in diabetes.

\section{Methods}

Induction and monitoring of diabetes in rats; drug treatments. Male Wistar rats were used in all experiments (Charles River Laboratories, Margate, Kent, UK). On arrival body weights were approximately $250 \mathrm{~g}$. Animals were housed for a week to allow settling and fasted overnight prior to induction of diabetes. Diabetes was induced using a single intraperitoneal injection $(50 \mathrm{mg} / \mathrm{kg}$ body weight) of streptozotocin (STZ) (SigmaAldrich Company, Gillingham, Dorset, UK) dissolved in $0.9 \%$ physiological saline immediately prior to use. Diabetic status was confirmed 3 days after induction by measurement of glucose levels in tail blood using glucose test strips (BMAccutest; Roche Diagnostics, Welwyn Garden City, Herts., UK). Rats were given free access to water and chow and main- tained for up to 12 weeks. Rats were killed by anaesthesia and exsanguinated in accordance with UK Home Office legislation; blood was handled as described below.

With the exception of fidarestat (see below) all treatments were begun 8 weeks after induction of diabetes and maintained for the final 4 weeks. At the 8 -week time point diabetic animals were allocated to treatment groups after weighing to preclude bias and achieve sub-groups with similar mean pretreatment weights. Normalisation of glycaemia with insulin was achieved by subcutaneous implantation of two Linplant pellets (Linshin Canada, Scarborough, Ont, Canada) under isoflurane anaesthesia. The implants gradually dissolve providing a sustained daily release of approximately 2 IU/implant. The human recombinant neurotrophins, NGF (a gift from Genentech, San Francisco, Calif., USA) and neurotrophin 3 (NT-3; a gift from Regeneron, Tarrytown, N.Y., USA) were given at the doses shown in the relevant figure three times per week (Monday, Wednesday, Friday) by subcutaneous injection. Fidarestat (a gift from Sanwa Kagaku Kenkyusho, Tokyo, Japan) treatment was begun at the end of week 2; animals received a daily oral dose of $2 \mathrm{mg} / \mathrm{kg}$ for 10 weeks.

Collection of plasma. Rat blood was obtained by exsanguination from the right ventricle under halothane anaesthetic in accordance with the Animals (Scientific Procedures) Act 1986. Samples were centrifuged (Megafuge 1.0; Heraeus Sepatech, Osterode/Harz, Germany) at $1000 \mathrm{~g}$ for 15 minutes. The plasma layer was transferred to a 4-ml internally threaded cryovial (Alpha Laboratories, Eastleigh, Hampshire, UK) and stored at $-40{ }^{\circ} \mathrm{C}$ until usage.

Plasma glucose determination. Hyperglycaemia was confirmed post-mortem using an ultra-violet (UV) D-glucose detection kit (Boehringer Mannheim, London, UK) adapted to 96-well plates. D-glucose is phosphorylated to glucose-6-phosphate in the presence of hexokinase and ATP. This is further oxidised by NADP catalysed by glucose-6-phosphate dehydrogenase to form gluconate-6-phosphate and NADPH. The increase in NADPH is measured utilising its absorbance of light at $340 \mathrm{~nm}$.

Glycated haemoglobin determination. After removal of plasma, red cells from rat blood were washed three times with $0.9 \%$ isotonic saline. The cleaned cells were haemolysed, and glycated haemoglobin was measured using a spectrophotometric assay (kit 441; Sigma-Aldrich) following manufacturer's instructions. A fresh cation-exchange resin column was used for each sample.

Fractionation of plasma proteins by SDS-PAGE. In initial studies, it was assumed that plasma albumin would interfere with measurement of $\mathrm{p} 75^{\mathrm{NTR}}$, since the latter was expected to be present in minor amounts compared to albumin. Thus the first method employed removed albumin using commercial affinity columns. Plasma was diluted $1+4$ with $0.02 \mathrm{~mol} / \mathrm{l}$ di-sodium hydrogen orthophosphate and $5 \mathrm{ml}$ loaded on to a Bio-Rad Econo-pac Blue Cartridge (Bio Rad, Hemel Hempstead, Herts., UK), prepared in accordance with the manufacturer's instructions. The sample was left on the column to equilibrate for 5 minutes and then plasma minus albumin eluted from the column with $5 \mathrm{ml} 0.02 \mathrm{mmol} / \mathrm{l}$ di-sodium hydrogen orthophosphate. Of this eluate, $80 \mu \mathrm{l}$ were added to $720 \mu \mathrm{l}$ of $0.02 \mathrm{~mol} / \mathrm{l}$ di-sodium hydrogen orthophosphate plus and $200 \mu \mathrm{LDS}$ and the mixture boiled for 5 minutes.

Subsequently it was discovered that the p75 NTR band could be effectively separated from albumin by PAGE (see Fig. 1), so the affinity column chromatography was abandoned and plasma samples were diluted directly with SDS. Samples 


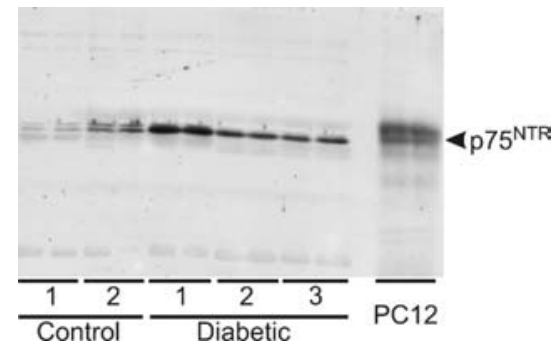

Fig. 1. Rat plasma western blots from SDS-PAGE, showing immunoreactivity to the p $75^{\mathrm{NTR}}$ antibody. Plasma extracts are duplicated in adjacent lanes, with samples from 2 control (nondiabetic ) rats, 3 rats with STZ-diabetes of 12 weeks duration and a lysate from PC12 cells, which express the p75 NTR

$(20 \mu \mathrm{l})$ were then run on $10 \%$ polyacrylamide gels in a running buffer comprising $0.025 \mathrm{~mol} / \mathrm{l}$ Tris, $0.192 \mathrm{~mol} / \mathrm{l}$ glycine, $0.1 \%$ $(\mathrm{w} / \mathrm{v}) \mathrm{SDS}, \mathrm{pH} 8.3$ at $120 \mathrm{~V}$ for 45 to 60 minutes. Proteins were then transferred to the nitrocellulose membranes and blocked for 1 hour at room temperature in Tris buffered saline containing Tween $(150 \mathrm{mmol} / \mathrm{l} \mathrm{NaCl}, 10 \mathrm{mmol} / \mathrm{l}$ Tris-HCL $\mathrm{pH} 7.6,0.05 \%$ Tween 20$)+10 \%$ milk substitute.

To enable comparison between gels, an external standard was always included in triplicate, using the two outer lanes, plus the centre lane. This comprised a standard amount of lysate from PC12 cells in culture, which express p75 NTR at a very high level. This rat adrenal phaeochromocytoma (PC12) cell line (ATCC [CRL 1721]) was obtained from the German Collection of Microorganisms and Cell Cultures (http://www.dsmz.de). Cells were grown in RPMI 1640 medium without glutamine, enriched with $10 \%$ heat-inactivated horse serum and 5\% fetal calf serum. To this was added $2 \mathrm{mmol} / \mathrm{l}$ glutamate and $1 \%$ penicillin-streptomycin (all components supplied by Gibco Life Technologies, Paisley, UK). Cells were grown in suspension and maintained at $37{ }^{\circ} \mathrm{C}$ in an environment consisting of $95 \%$ air and $5 \% \mathrm{CO}_{2}$. At infrequent intervals large cultures were prepared and the cells lysed to produce several hundred identical aliqots for use with plasma gels. Lysates were stored for up to 1 year at $-70{ }^{\circ} \mathrm{C}$.

The membranes were incubated overnight at $4{ }^{\circ} \mathrm{C}$ with antihuman $7^{\mathrm{NTR}}$ antibody at 1:5000 dilution in TBS Tween $+0.1 \%$ sodium azide $(20 \mathrm{ml})$. Membranes were washed $(3 \times 15$ minutes) at room temperature in TBS Tween and incubated with secondary antibody, i.e. Anti rabbit (New England Biolabs, Hitchin, Herts., UK) 1:5000 dilution in TBS Tween for 1 hour at room temperature $(20 \mathrm{ml})$. This was followed by 3 further washes (each 15 minutes) in TBS Tween. Finally, membranes were exposed to standard Lumiglo (New England Biolabs) chemiluminescence enhancement and exposed to $\mathrm{X}$ ray film for 10 to 30 seconds.

Special animal studies. In one experiment plasma samples from diabetic mice lacking the gene coding for $\mathrm{p} 75^{\mathrm{NTR}}$ were compared with those from wild-type mice. Plasma samples from exon-3 hypomorphic mice ( $75^{N T R}$ exonIII-/-) were a kind gift from Professor Johannes Jakobsen (Dept. Neurology, Århus University, Denmark). Exon III encodes the ligand-binding site of p75 ${ }^{\mathrm{NTR}}$, deletion of this exon results in a knock-out phenotype unable to respond to neurotrophins $[15,16]$. These transgenic mice continue to produce $\mathrm{p} 75^{\mathrm{NTR}}$ isoforms, generated from a splice variant of the $p 75^{N T R}$ gene, which results in incomplete ablation of the wild-type phenotype [17]. Balbc mice were used as a wild-type control.

In a separate study unilateral sciatic nerve crushes were performed on healthy male Wistar rats to determine whether
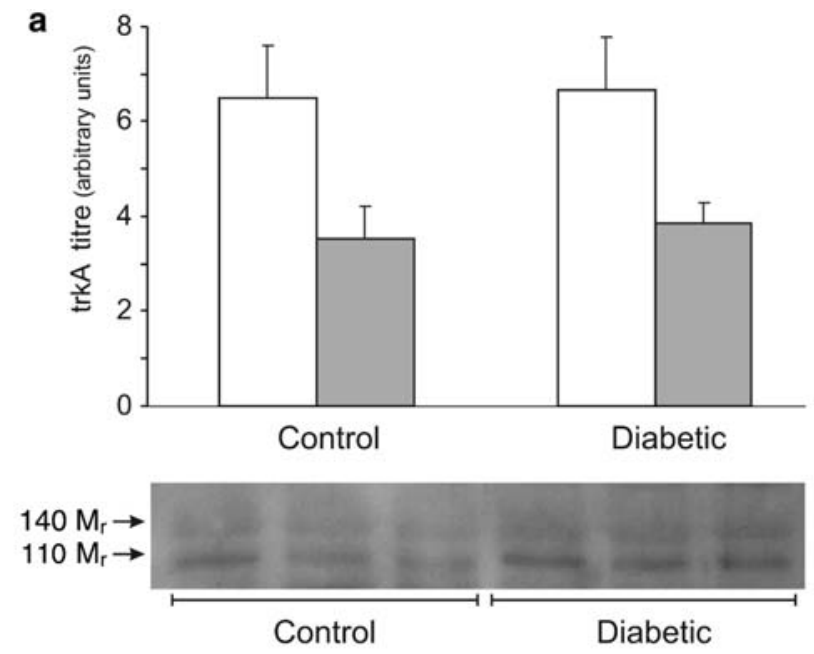

b

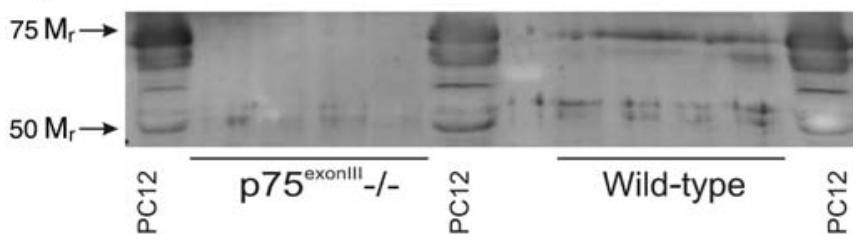

Fig. 2 a. Immunoreactivity to the trkA antibody in plasma from control and diabetic rats. As in nervous tissue, 110 (open bars) and $140-\mathrm{M}_{\mathrm{r}}$ (grey bars) components were present, but only in trace amounts and no differences were seen between control and diabetic rats. b. Plasma from p75(-/-) and wildtype diabetic mice showing p75 NTR immunoreactivity in 75 and $50-\mathrm{M}_{\mathrm{r}}$ fractions. No $75-\mathrm{M}_{\mathrm{r}}$ IR was found in the $(-/-)$ mice and the $50-\mathrm{M}_{\mathrm{r}}$ fraction was much reduced

such axonal trauma could result in the appearance of p75 NTR immunoreactivity in plasma. Rats were anaesthetised with isoflurane (initial anaesthesia achieved using 5\% isoflurane in oxygen and maintained by $1.5 \%$ isoflurane in oxygen). Left sciatic nerves were crushed at mid-thigh level for 15 seconds using watchmaker forceps. This was repeated once more at the same site. Animals were allowed to recover and were maintained for 2 to 14 days before being killed and exsanguinated.

\section{Results}

p75NTR immunoreactivity in plasma gels. Figure 1 shows a typical gel from rat plasma, illustrating the separation of $\mathrm{p} 75^{\mathrm{NTR}}$ immunoreactivity (IR). In spite of the potential conflict with $70 \mathrm{M}_{\mathrm{r}}$ albumin, $\mathrm{p} 75^{\mathrm{NTR}}$ IR was easily resolved and the bands scanned. In most samples, two reactive bands were present, neither of which was present in blots exposed to secondary antibody only. The increase in titre in samples from diabetic rats is clearly illustrated in this gel; for quantification of this effect, see below.

Figure 2a shows that traces of trkA IR were also present in rat plasma; it was not seen in human plasma. There were no differences in titre in plasma for either the $110 \mathrm{M}_{\mathrm{r}}$ or the full-length $140 \mathrm{M}_{\mathrm{r}}$ trkA IR 


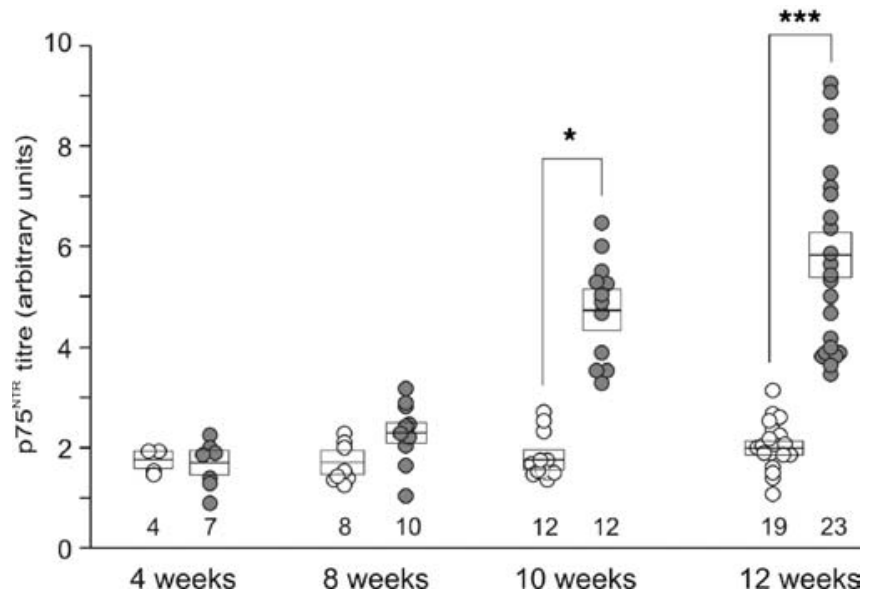

Fig. 3. The time-course of appearance of $p 75^{\mathrm{NTR}}$ IR in plasma of diabetic rats (filled circles) compared to controls (open circles). Circles represent individual animals, horizontals are group means, boxes indicate $\pm 1 \mathrm{SD}$. The values below indicate the numbers of rats per group. $* p<0.05 ; * * * p<0.001$

between control rats and rats 12 weeks after induction of diabetes with STZ.

Figure $2 b$ shows a comparison of the $\mathrm{p} 75$ region of immunoblots from plasma taken from wild-type Balbc $(p 75+/+)$ and $p 75-/-$ mice, both with STZ-induced diabetes of 4 weeks duration. There was no IR in the p75 region of the $-/-$ mice, but a clear doublet was present in this region of wild-type mice.

Time course of effects of diabetes in rats. Figure 3 shows data for individual animals, together with means and SEMs for groups of rats with STZ-induced diabetes of 4 to 12 weeks duration. No increase in plasma $75^{\text {NTR }}$ IR was associated with 4 weeks diabetes, but significant increases were present at 10 and 12 weeks. The beginning of this trend was visible at 8 weeks after induction of diabetes.

This time course study served as a baseline for subsequent testing of interventions. In each study, animals were untreated for the first 8 weeks of diabetes, but treatment was then implemented for the last four weeks of a 12-week diabetes protocol.

Effects of insulin. Figure 4a shows the effect of maintaining tight glycaemic control on plasma p $75^{\mathrm{NTR}} \mathrm{IR}$ (parameters of glycaemic control, see Table 1). Note that insulin treatment in the last 4 weeks of a 12-week protocol normalised plasma glucose and glycated haemoglobin, and significantly increased body weight at the end of the study. Plasma p75NTR IR was also normalised in the insulin-treated group.

Effect of aldose reductase inhibition. Inhibition of aldose reductase with fidarestat had no effect on body weight or plasma glucose (Table 1), but normalised sciatic nerve sorbitol and fructose (Table 2). The treatment also normalised plasma p75 ${ }^{\text {NTR }}$ IR (Fig. 4b).
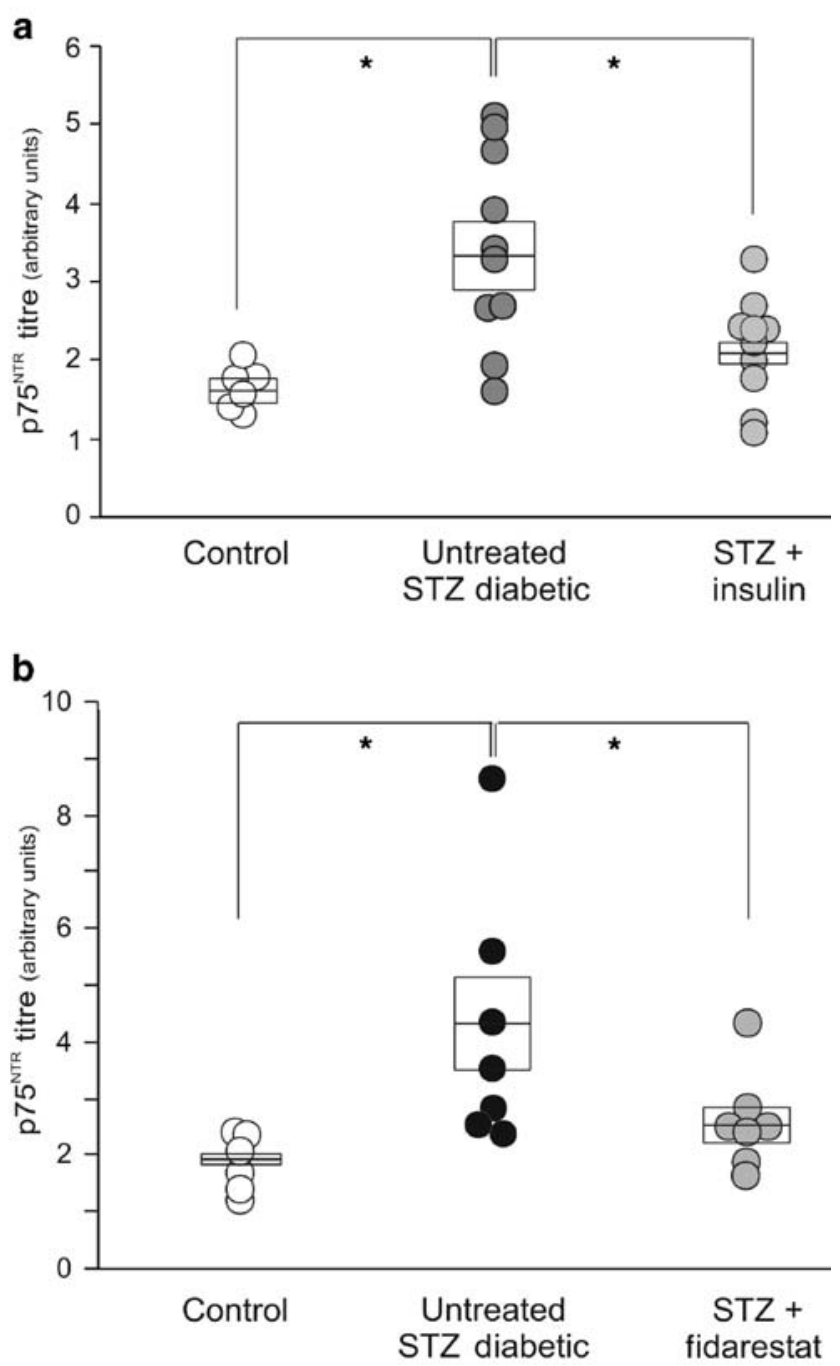

Fig. 4. Effects of insulin (a) and the aldose reductase inhibitor, fidarestat (b), on appearance of p75 ${ }^{\mathrm{NTR}}$ IR in plasma of diabetic rats. Key to symbols, see legend Figure 3. $* p<0.05$

Effect of neurotrophins. Treatment with either NGF or NT-3 had no effect on the indices of diabetes, i.e. body weight and either plasma glucose or glycated haemoglobin (Table 1). However, as Figure 5 shows, both neurotrophins reduced and normalised the p75 ${ }^{\text {NTR }}$ IR titre in plasma in a dose-dependent manner.

Effect of nerve crush without diabetes. The central premise for this work was that metabolic stress applied to neurones or Schwann cells could give rise to shedding of the $\mathrm{p} 75^{\mathrm{NTR}}$ receptor, leading to its appearance in plasma. Indirect support for this hypothesis was sought by inflicting nerve damage in the form of a crush injury to one sciatic nerve. After this operation, rats were killed after 2,7 or 14 days, with sham operations conducted on control animals for the 7 and 14-day time points. Plasma from these samples was gel-fractionated, blotted and exposed to the p75 NTR antibody as shown in Figure 6. There was clear immunoreactivity at the 14-day time point, with an upward 
Table 1. Indices of diabetes in rats with insulin implants or with NGF, NT-3 or aldose reductase inhibitor treatment, compared with untreated control and diabetic rats

\begin{tabular}{|c|c|c|c|}
\hline & Body weight (g) & Plasma glucose $(\mathrm{mmol} / \mathrm{l})$ & Glycated haemoglobin (\%) \\
\hline Control $(n=6)$ & $458 \pm 15$ & $6.8 \pm 1.0$ & $2.3 \pm 0.3$ \\
\hline Untreated diabetic $(n=10)$ & $291 \pm 42$ & $34.3 \pm 6.4$ & $4.8 \pm 0.9$ \\
\hline Control $(n=6)$ & $634 \pm 42$ & & $2.4 \pm 0.3$ \\
\hline Untreated diabetic $(n=10)$ & $421 \pm 49$ & & $5.8 \pm 0.6$ \\
\hline Diabetic + NGF $0.1 \mathrm{mg} / \mathrm{kg}(n=10)$ & $416 \pm 33$ & & $5.7 \pm 0.3$ \\
\hline Untreated diabetic $(n=10)$ & $342 \pm 11$ & $33.0 \pm 1.1$ & \\
\hline Diabetic + NT-3 $1 \mathrm{mg} / \mathrm{kg}(n=10)$ & $347 \pm 20$ & $35.3 \pm 2.8$ & \\
\hline Diabetic + NT-3 $5 \mathrm{mg} / \mathrm{kg}(n=10)$ & $387 \pm 14$ & $34.0 \pm 1.7$ & \\
\hline Control $(n=9)$ & $631 \pm 20$ & $7.0 \pm 0.3$ & \\
\hline Untreated diabetic $(n=10)$ & $359 \pm 8$ & $28.9 \pm 1.1$ & \\
\hline Diabetic + fidarestat $(n=10)$ & $362 \pm 14$ & $31.6 \pm 1.2$ & \\
\hline
\end{tabular}

Duration of diabetes was 12 weeks, insulin implants were present for the last 4 weeks. NGF or NT-3 were given at the doses cited by subcutaneous injection 3 times per week for the last 4 weeks. Data are mean $\pm 1 \mathrm{SD}$; blank cells indicate that the variable was not measured. For all variables diabetic rats were sig- nificantly different than the other two groups $(p<0.001$ by oneway ANOVA with Student-Neuman-Keuls range tests), except for insulin-treated diabetic rats, which were not different from controls, but were significantly different $(p<0.001)$ from untreated diabetic rats

Table 2. Effects of diabetes and fidarestat treatment on polyol pathway metabolites in the sciatic nerve

\begin{tabular}{|c|c|c|c|c|}
\hline & Glucose & Fructose & Sorbitol & myo-Inositol \\
\hline Control $(n=9)$ & $6.9 \pm 1.2$ & $4.7 \pm 1.0$ & $0.9 \pm 0.4$ & $13.3 \pm 3.0$ \\
\hline Untreated diabetic $(n=10)$ & $36.1 \pm 2.1$ & $14.7 \pm 0.8$ & $6.2 \pm 0.7$ & $5.2 \pm 0.8$ \\
\hline
\end{tabular}

Data are means \pm SEM in $\mathrm{nmol} / \mathrm{mg}$ dry tissue. For all variables untreated diabetic rats were significantly different than controls and significantly different than diabetic rats treated with fidarestat $(p<0.01$ by one-way ANOVA with Student-Neuman-Keuls range tests), except for glucose trend at 7 days. Neither sham operation was associated with increased appearance of $\mathrm{p} 75^{\mathrm{NTR}}$ in plasma.

\section{Discussion}

It is clear from these studies that $\mathrm{p} 75^{\mathrm{NTR}} \mathrm{IR}$ appears in plasma in rats with STZ-induced diabetes and that the titre increases with increasing duration of the disease. The IR is specific, in that incubation of blots without primary antibody gave no product in the $75-\mathrm{M}_{\mathrm{r}}$ region of the blot and product was absent from the plasma of $p 75^{N T R}(-/-)$ mice. In a pilot study of plasma from human volunteers, p75 ${ }^{\mathrm{NTR}}$ IR was present and the titre was higher in diabetic subjects. So far this latter observation has not been quantified nor has a possible association with neuropathy been explored; this is the subject of on-going investigation. Nevertheless, our pilot studies with human plasma underline the relevance of the rat data presented here.

The main object of these studies was to validate the specificity and time course of appearance of p $75^{\mathrm{NTR}}$, as defined above, but then to explore a series of inter- ventions that might influence the titre in plasma of diabetic rats. Treatment with insulin was obviously essential to differentiate between diabetes as a prime cause of $\mathrm{p} 75^{\mathrm{NTR}}$ appearance and other potential influences, such as non-specific effects of STZ. Prevention of appearance by insulin was perfectly clear. This suggests, but does not prove that hyperglycaemia is a cause. The fact that the aldose reductase inhibitor, fidarestat, prevented the appearance of $\mathrm{p} 75^{\mathrm{NTR}} \mathrm{IR}$ in plasma strengthens the above suggestion. Exaggerated flux through aldose reductase and the polyol pathway-the target of an aldose reductase inhibitor-is driven directly by intracellular glucose resulting from elevated extracellular glucose (see [18] for recent review).

The observation that the $\mathrm{p} 75^{\mathrm{NTR}}$ was present in the plasma of diabetic wild-type mice, but absent from the plasma of the p75 NTR (-/-) mouse also argues against STZ as a causative agent and strengthens the conclusion that the plasma immunoreactivity reflects "real" p75 receptor protein.

The effect of fidarestat may also indicate that plasma $\mathrm{p} 75^{\mathrm{NTR}}$ IR serves as a marker of efficacy for 

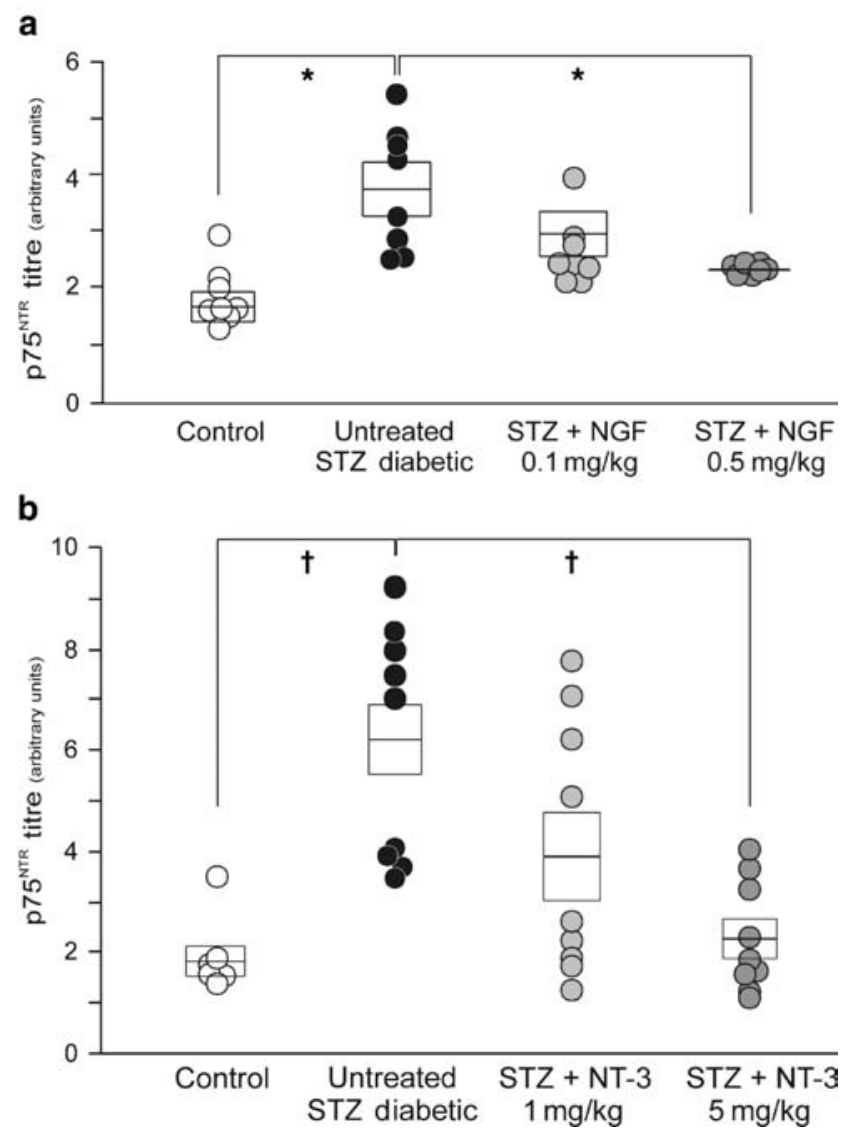

Fig. 5. Effects of the neurotrophins NGF (a) and NT-3 (b) on appearance of p75 NTR IR in plasma of diabetic rats. Key to symbols, see legend to Figure $3 .{ }^{*} p<0.05 ; \dagger p<0.005$

agents that ameliorate at least some of the factors responsible for diabetic neuropathy. For example, it is well established that aldose reductase inhibitors prevent nerve conduction deficits in experimental diabetic neuropathy [19] and attenuate these deficits in the clinic [20]. The effects of the neurotrophins support this. Both NGF and NT-3 normalised the plasma level of $\mathrm{p} 75^{\mathrm{NTR}}$ at the higher of the two doses used. The lack of effect at the lower doses suggests that there is a pharmacological (i.e. dose-related) effect. Since both of these molecules bind to p75 NTR and this binding is implicated in their capacity to signal through the trk receptors $[21,22,23]$, the loss of $\mathrm{p} 75^{\mathrm{NTR}}$ receptors into plasma may reflect the deficits in both NGF and NT-3 that are clearly present in experimental diabetes $[24,25,26]$.

It has long been known that the p75 NTR is not specific for nervous tissue [27] and its production in neoplasias, especially prostate cancers, is well established $[28,29,30]$. Hence, it cannot be assumed that the p75 NTR immunoreactivity detected in plasma is certain to have originated in nervous tissue. Absolute proof of this would require generation of a transgenic animal carrying a mutant $\mathrm{p} 75^{\mathrm{NTR}}$ on neurone- and Schwanncell-specific promoters. Rather than go to such lengths, we performed the nerve crush study, which

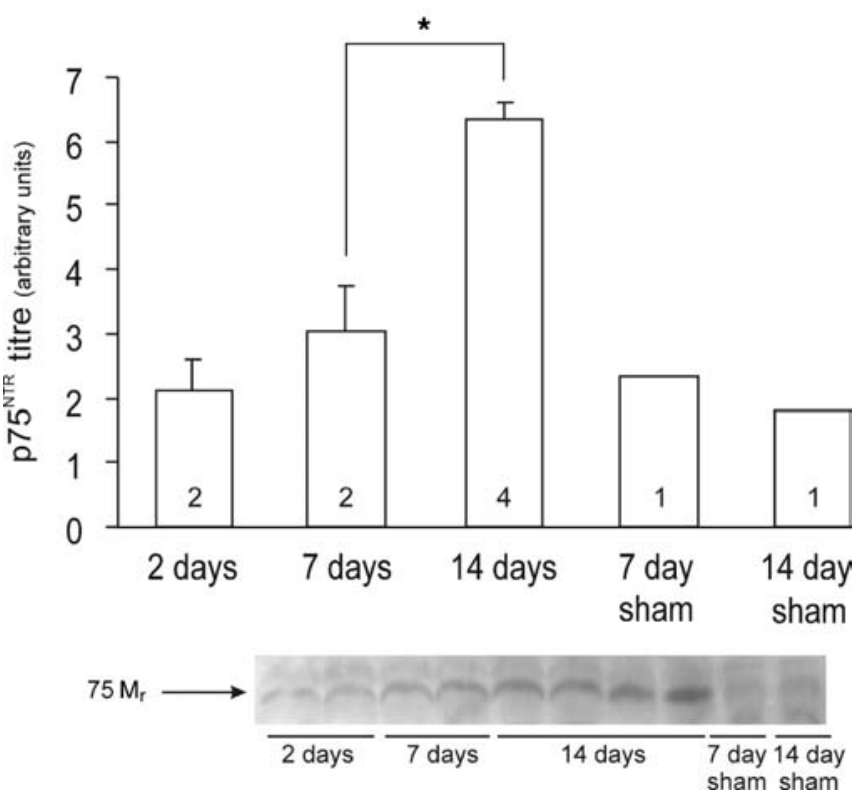

Fig. 6. Effects of a unilateral sciatic nerve crush injury on appearance of p $75^{\mathrm{NTR}}$ IR in plasma of normal (i.e. non-diabetic) rats. $* p<0.05$

does show that nerve trauma can cause a measurable elevation of plasma $\mathrm{p} 75^{\mathrm{NTR}}$ immunoreactivity. This, taken together with the effect on this immunoreactivity of neuronally-targeted agents, such as NGF and NT-3, strongly suggests that the plasma $\mathrm{p} 75^{\mathrm{NTR}}$ immunoreactivity does originate from peripheral nerve and might indicate an abnormality therein.

Other studies have examined the status of $\mathrm{p} 75^{\mathrm{NTR}}$ in peripheral nerve in diabetes. In diabetic rats, increased expression of $\mathrm{p} 75^{\mathrm{NTR}}$ immunoreactivity was observed in sciatic nerve without signs of degeneration [31]. In contrast a human study observed increased $\mathrm{p} 75^{\mathrm{NTR}}$ immunoreactivity in teased fibres only in patients with established neuropathy and fibre degeneration [32]. However, another study failed to detect abnormalities in p75 NTR immunoreactivity in human nerve in association with degeneration and failure of regeneration [33]. Notwithstanding this latter observation, there are grounds for suggesting that maintenance/expression of $\mathrm{p} 75^{\mathrm{NTR}}$ in nerve in diabetes is abnormal, so that the increase in plasma titre reported here probably has its origins in peripheral nerve.

This study concentrated on effects of interventions, but a thorough demonstration of a relationship between the plasma p75 NTR immunoreactivity titre and diabetic neuropathy would require close correlation with structural and functional indices of the condition. This can only be done on a limited basis in rodents; hence a clinical study addressing these issues is now in progress.

Acknowledgements. This study was started with support from Diabetes UK and continued under NIH grant Ro1 NS4625901 . We are grateful to Genentech for a gift of NGF, to Sanwa 
for fidarestat and to Johannes Jakobsen and Yun Jiang for plasma from mice. The authors have no conflicts of interest in respect of this work.

\section{References}

1. Chen TC, Hinton DR, Sippy BD, Hofman FM (1997) Soluble TNF-alpha receptors are constitutively shed and downregulate adhesion molecule expression in malignant gliomas. J Neuropathol Exp Neurol 56:541-550

2. Pellegrini JD, Puyana JC, Lapchak PH, Kodys K, MillerGraziano CL (1996) A membrane TNF-alpha/TNFR ratio correlates to MODS score and mortality. Shock 6:389-396

3. Alaaeddine N, DiBattista JA, Pelletier JP et al. (1997) Osteoarthritic synovial fibroblasts possess an increased level of tumor necrosis factor-receptor 55 (TNF-R55) that mediates biological activation by TNF-alpha. J Rheumatol 24:1985-1994

4. Sippy BD, Hofman FM, Wright AD, He S, Ryan SJ, Hinton DR (1996) Soluble tumor necrosis factor receptors are present in human vitreous and shed by retinal pigment epithelial cells. Exp Eye Res 63:311-317

5. Levine SJ, Logun C, Chopra DP, Rhim JS, Shelhamer JH (1996) Protein kinase C, interleukin-1 beta, and corticosteroids regulate shedding of the type I, $55 \mathrm{kDa}$ TNF receptor from human airway epithelial cells. Am J Respir Cell Mol Biol 14:254-261

6. Hommes DW, Meenan J, de Haas M et al. (1996) Soluble Fc gamma receptor III (CD 16) and eicosanoid concentrations in gut lavage fluid from patients with inflammatory bowel disease: reflection of mucosal inflammation. Gut 38:564-567

7. Nielsen $\mathrm{OH}$, Ciardelli T, Wu Z, Langholz E, Kirman I (1995) Circulating soluble interleukin-2 receptor alpha and beta chain in inflammatory bowel disease. Am J Gastroenterol 90:1301-1306

8. Sadouk MB, Pelletier JP, Tardif G, Kiansa K, Cloutier JM, Martel-Pelletier J (1995) Human synovial fibroblasts coexpress IL-1 receptor type I and type II mRNA. The increased level of the IL-1 receptor in osteoarthritic cells is related to an increased level of the type I receptor. Lab Invest 73:347-355

9. Chen A, Engel P, Tedder TF (1995) Structural requirements regulate endoproteolytic release of the L-selectin (CD62L) adhesion receptor from the cell surface of leukocytes. J Exp Med 182:519-530

10. Rebuck N, Gibson A, Finn A (1995) Neutrophil adhesion molecules in term and premature infants: normal or enhanced leucocyte integrins but defective L-selectin expression and shedding. Clin Exp Immunol 101:183-189

11. Goebeler M, Kaufmann D, Brocker EB, Klein CE (1996) Migration of highly aggressive melanoma cells on hyaluronic acid is associated with functional changes, increased turnover and shedding of CD44 receptors. J Cell Sci 109:1957-1964

12. Chao MV, Hempstead BL (1995) p75 and Trk: a two-receptor system. Trends Neurosci 18:321-326

13. DiStefano PS, Johnson EM Jr (1988) Identification of a truncated form of the nerve growth factor receptor. Proc Natl Acad Sci USA 85:270-274

14. Hruska RE, Chertack MM, Kravis D (1993) Elevation of nerve growth factor receptor-truncated in the urine of patients with diabetic neuropathy. Ann NY Acad Sci 679:349-351
15. Lee K-F, Li E, Huber LJ et al. (1992) Targeted mutation of the gene encoding the low affinity NGF receptor p75 leads to deficits in the peripheral sensory nervous system. Cell 69:737-749

16. Bergmann I, Priestley JV, McMahon SB, Brocker EB, Toyka KV, Koltzenburg M (1997) Analysis of cutaneous sensory neurons in transgenic mice lacking the low affinity neurotrophin receptor p75. Eur J Neurosci 9:18-28

17. Von Schack D, Casademunt E, Schweigreiter R, Meyer M, Bibel M, Dechant G (2001) Complete ablation of the neurotrophin receptor p75NTR causes defects both in the nervous and the vascular system. Nat Neurosci 4:977-978

18. Oates PJ (2002) Polyol pathway and diabetic peripheral neuropathy. Int Rev Neurobiol 50:325-392

19. Tomlinson DR, Holmes PR, Mayer JH (1982) Reversal, by treatment with an aldose reductase inhibitor, of impaired axonal transport and motor nerve conduction velocity in experimental diabetes mellitus. Neurosci Lett 31:189-193

20. Santiago JV, Sönksen PH, Boulton AJ et al. (1993) Withdrawal of the aldose reductase inhibitor tolrestat in patients with diabetic neuropathy: effect on nerve function. The Tolrestat Study Group. J Diabet Complications 7:170-178

21. Huang EJ, Reichardt LF (2003) TRK receptors: roles in neuronal signal transduction. Annu Rev Biochem 72:609-642

22. Friedman WJ, Greene LA (1999) Neurotrophin signaling via Trks and p75. Exp Cell Res 253:131-142

23. Frade JM, Barde YA (1998) Nerve growth factor: two receptors, multiple functions. BioEssays 20:137-145

24. Fernyhough P, Diemel LT, Hardy J, Brewster WJ, Mohiuddin L, Tomlinson DR (1995) Human recombinant nerve growth factor replaces deficient neurotrophic support in the diabetic rat. Eur J Neurosci 7:1107-1110

25. Tomlinson DR, Fernyhough P, Diemel LT (1996) Neurotrophins and peripheral neuropathy. Philos Trans R Soc Lond B Biol Sci 351:455-462

26. Fernyhough P, Diemel LT, Tomlinson DR (1998) Target tissue production and axonal transport of neurotrophin-3 are reduced in streptozotocin-diabetic rats. Diabetologia 41:300-306

27. Alpers CE, Hudkins KL, Ferguson M, Johnson RJ, Schatteman GC, Bothwell M (1993) Nerve growth factor receptor expression in fetal, mature, and diseased human kidneys. Lab Invest 69:703-713

28. Walch ET, Marchetti D (1999) Role of neurotrophins and neurotrophin receptors in the in vitro invasion and heparanase production of human prostate cancer cells. Clin Exp Metastasis 17:307-314

29. Sortino MA, Condorelli F, Vancheri C et al. (2000) Mitogenic effect of nerve growth factor (NGF) in $\mathrm{LNCaP}$ prostate adenocarcinoma cells: role of the high- and low-affinity NGF receptors. Mol Endocrinol 14:124-136

30. Weeraratna AT, Arnold JT, George DJ, DeMarzo A, Isaacs JT (2000) Rational basis for trk inhibition therapy for prostate cancer. Prostate 45:140-148

31. Conti G, Stoll G, Scarpini E et al. (1997) p75 neurotrophin receptor induction and macrophage infiltration in peripheral nerve during experimental diabetic neuropathy: possible relevance on regeneration. Exp Neurol 146:206-211

32. Scarpini E, Conti G, Chianese L et al. (1996) Induction of p75 NGFR in human diabetic neuropathy. J Neurol Sci 135:55-62

33. Bradley JL, Thomas PK, King RH et al. (1995) Myelinated nerve fibre regeneration in diabetic sensory polyneuropathy: correlation with type of diabetes. Acta Neuropathol (Berl) 90:403-410 